\title{
Influences of Proximate Determinates on Fertility Among Urban and Rural Women in Bangladesh
}

\author{
Muhammad Mahmudul Hasan ${ }^{1}$, Mirajul Islam ${ }^{1}$, Md. Saifullah Sakib ${ }^{2}$ and Md. Iqramul Haq ${ }^{2}$ \\ ${ }^{1}$ Department of Statistics, Dhaka University, Dhaka-1000, Bangladesh \\ ${ }^{2}$ Department of Statistics, Jagannath University, Dhaka- 1100, Bangladesh
}

( Received: 24 September 2017 ; Accepted : 27 November 2017)

\begin{abstract}
Bangladesh has met a lot of challenges in recent decades. The remarkable decline in fertility is one of the major challenges faced by this country. The rate of fertility in rural areas is still higher than urban areas. The proximate determinants of fertility which influence fertility directly are analyzed in this study for urban and rural areas separately as well as the study quantify the decomposition of the differences in total fertility rate (TFR) in residence during 1993-94 to 2014. The effectiveness of contraceptive use is found to be the most important factor for declining fertility. The result revealed that the index of contraception shows a declining trend, indicating an increasingly inhibiting effect on fertility in both urban and rural areas of Bangladesh. The inhibition effect of postpartum infecundability decreases with increase in urbanization. The decomposition analysis shows that fertility decline has been occurred due to delay marriage, increase of contraception practice, shortening of postpartum infecundability period, increase proportion in induced abortion and the interaction factor.
\end{abstract}

Keywords: Fertility, Postpartum insusceptibility, Use effectiveness, Contraceptive Prevalence, Abortion rate.

\section{Introduction}

The size, composition and structure of a country is determined by its fertility behavior.According ${ }^{2}$ to the Bangladesh Bureau of Statistics (BBS) in 2014, the total population in Bangladesh is about 0.158 billion and the population density is 1,070 persons per square kilometer. The population expanded by 8 million, with an annual increase of above 2.0 million from 2011 to 2014.

A remarkable decrease in TFR is observed in Bangladesh Demographic and Health Survey (BDHS), 2014. The report shows that the total fertility rate (TFR) decreases from 6.3 to 2.3 births per woman from 1975 to 2014. Beside this, a high increase in the contraceptive prevalence rate (CPR) is detected from BDHS, 2014. The CPR which was 7.7\% in 1975 increased to $62.4 \%$ in 2014. The 2014 BDHS data show that the TFR in Bangladesh has become stagnant since 2011. The TFR in urban areas is 2.0 per woman but it is 2.4 in rural areas.

Researchers, policy makers, and academics are very much interested in the recent decrease in fertility occurred in Bangladesh. Among the Asian countries, the main reason of fertility declining for the women from poor family was the use of effective contraceptive ${ }^{9}$.A study showed improvements in the wealth index, healthy life and other social factors which are necessary for fertility decline ${ }^{1}$. The family planning program was one of the key factors for declining trend of fertility ${ }^{5}$.These programs raised the CPR from $8 \%$ in 1975 to $44 \%$ in $1993-94^{11}$. It can be inferred that socioeconomic factors such as education, female employment are not the main factors for the decreasing trend of fertility ${ }^{3}$.

Human reproduction is not considered as a simple process and it is usually affected by a number of biological, cultural and behavioral factors ${ }^{4}$. It is also said that biological as well as behavioral factors are true proximate determinants of fertility. This is obvious that if one of the proximate determinants changes then the total fertility will also be changed. But for a change in background determinants of fertility such as income, education, media exposure will not necessarily makes a change in fertility. Actually, fertility is affected by socioeconomic factors indirectly through their impact on proximate determinants.

The impact of proximate determinants on fertility is an important issue in population growth analysis in Bangladesh. Since these impacts are different in both Urban and rural areas. Our present study examines the influence of proximate determinants in fertility in urban and rural areas in Bangladesh separately for the ten years interval which are 1993-94, 2004 and 2014 BDHS survey.

\section{Data Source and Method of Analysis}

\section{Data Source}

The analysis is based on secondary data obtained from the1993-94, 2004 and 2014 Bangladesh Demographic and Health Surveys (BDHSs). In this study, we have considered women aged 15-49. Based on these criteria, sample sizes for this study were 9495, 11290 and 17863 ever-married women for 1993-94, 2004 and 2014 BDHS data, respectively.

\section{Estimation of Proximate Determinant Indices}

Bongaarts ${ }^{4}$ suggested that the TFR could be expressed as the multiplication of four indices i.e. index of marriage, index of contraception, index of abortion and index of postpartum infecundability with the total fecundity rate (TF).

According to the Bongaarts model,

$$
\begin{aligned}
T F R=C_{m} \times C_{c} & \times C_{a} \times C_{i} \\
& \times T F
\end{aligned}
$$

Where, Index of marriage $\left(C_{m}\right)=$ $\{1$, if all the women ages 15 to 49 are married

$\left\{\begin{array}{r}1, \text { if they are not married } \\ \text { in }\end{array}\right.$

Index of effective contraception $\left(C_{c}\right)=$

$\{1$, if no use of contraception

$\{$, if all use effective contraception

Index of induced abortion $\left(C_{a}\right)=$

$\{1$, if no induced abortion occur

$\{$, if induced abortion occur 
Index of postpartum infecundability $\left(C_{i}\right)=$

$\{1$, if the lactation is absent and postpurtam abstinence occur 0 , if the length of infecundabilityis not finite

\section{The Index of Marriage}

The index of marriage can be obtained dividing the TFR by the total marital fertility rate (TMFR). That is, $C_{m}=$ TFR/TMFR. The women who were living together are weighed as married.

\section{The Index of Postpartum infecundability}

The index of postpartum infecundability denoted by $C_{i}$ is expressed as;

$$
C_{i}=\frac{20}{(18.5+\mathrm{i})}
$$

Here, $i$ is the average duration of postpartum infecundability due to breastfeeding or postpartum abstinence.

\section{The Index of Contraception}

The index of contraception denoted by $\mathrm{Cc}$ is,

$$
C_{c}=1-1.08 \times \mathrm{u} \times \mathrm{e}
$$

where, $\mathrm{u}$ is the use of current contraceptive among married women aged from 15 to 49 and $\mathrm{e}$ is the effectiveness measure of average contraception use. The value of adjustment factor is 1.08. The reason for using adjustment factor is the sterility of some women.

\section{The Index of Induced Abortion}

The index of induced abortion is as follows:

$$
C_{a}=\mathrm{TFR} /(\mathrm{TFR}+.4 \times(1+\mathrm{u}) \times \mathrm{TA})
$$

Where, TA is the total abortion rate and it is calculated by similar manner way of age specific fertility rate (ASFR), but here denominator is the number of abortions in the last year among pregnant women rather than number live births in the last year.

Therefore, Total Abortion is calculated by

\section{$\mathrm{TA}=5 * \mathrm{ASFR}$}

Decomposition of the Change in Fertility and Contribution of Proximate Variables

The level of fertility is changed when at least one of the proximate determinants changes. To quantify the effect of the proximate determinants on fertility, a decomposition method is used in our study. The decomposition of the proportional change in the TFR occurred due to changes in proximate determinants with the interaction factor ${ }^{6}$.

Suppose 2004 is the first and 2014 is the recent years for which decomposition is performed. Let $\mathrm{TFR}_{2004}$ and $\mathrm{TFR}_{2014}$ be the TFRs in the years 2004 and 2014, respectively. Similarly the four indices are $\mathrm{Cm}_{2004}, \mathrm{Cc}_{2004}$, $\mathrm{Ca}_{2004}$ and $\mathrm{C}_{2004}$ for the year 2004 and $\mathrm{Cm}_{2014}, \mathrm{Cc}_{2014}, \mathrm{Ca}_{2014}$ and $\mathrm{Ci}_{2014}$ for the year 2014. The total fertilities (TFs) for 2004 and 2014 are $\mathrm{TF}_{2004}$ and $\mathrm{TF}_{2014}$, respectively. Then the ratio $\frac{\text { TFR } 2014}{\text { TFR }_{2004}}$ can be written as :
$\frac{\mathrm{TFR}_{2014}}{\mathrm{TFR}_{2004}}=\frac{\mathrm{Cm}_{2014}}{\mathrm{Cm}_{2004}} \times \frac{\mathrm{Cc}_{2014}}{\mathrm{Cc}_{2004}} \times \frac{\mathrm{Ca}_{2014}}{\mathrm{Ca}_{2004}} \times \frac{\mathrm{Ci}_{2014}}{\mathrm{Ci}_{2004}} \times \frac{\mathrm{TF}_{2014}}{\mathrm{TF}_{2004}}$

where $P_{f}=\frac{T_{F R} 2014}{T_{F R} 2004}-1$ is the total proportional change in TFR andP $_{\mathrm{m}}=\frac{\mathrm{Cm}_{2014}}{\mathrm{Cm}_{2004}}-1, \mathrm{P}_{\mathrm{c}}=\frac{\mathrm{Cc}_{2014}}{\mathrm{Cc}_{2004}}-1, \quad \mathrm{P}_{\mathrm{a}}=\frac{\mathrm{Ca}_{2014}}{\mathrm{Ca}_{2004}}-1, \quad \mathrm{P}_{\mathrm{i}}=$ $\frac{\mathrm{C} i_{2014}}{\mathrm{C} i_{2004}}-1$ as well as $\mathrm{P}_{\mathrm{r}}=\frac{\mathrm{TF}_{2014}}{\mathrm{TF}_{2004}}-1$ are the changes in TFR for the causes of marriage index, index of contraception, induced abortion and the remaining proximate variables, respectively between 2004 and 2014.

Therefore, the proportional change in TFR can be written as $\mathrm{P}_{\mathrm{f}}=\mathrm{P}_{\mathrm{m}}+\mathrm{P}_{\mathrm{c}}+\mathrm{P}_{\mathrm{a}}+\mathrm{P}_{\mathrm{i}}+\mathrm{P}_{\mathrm{r}}+\mathbf{i}$

where the symbol indicates interaction factor.

The above formulas can be used for calculating the proportions of changes in TFR between 2004 and 2014. In our study, we have used the above formulas to calculate the proportional change from 1993-94 to 2004 and then 2004 to 2014.

\section{Absolute Change in Fertility}

From above equation we have $\mathrm{P}_{\mathrm{f}}=\mathrm{P}_{\mathrm{m}}+\mathrm{P}_{\mathrm{c}}+\mathrm{P}_{\mathrm{a}}+\mathrm{P}_{\mathrm{i}}+\mathrm{P}_{\mathrm{r}}+\mathbf{i}$

Multiplying above equation by $\mathrm{TFR}_{2004}$ will give in the following equation:

$\mathrm{TFR}_{2014}-\mathrm{TFR}_{2004}=\mathrm{TFR}_{2004}\left(\mathrm{P}_{\mathrm{m}}+\mathrm{P}_{\mathrm{c}}+\mathrm{P}_{\mathrm{a}}+\mathrm{P}_{\mathrm{i}}+\mathrm{P}_{\mathrm{r}}+\right.$ I) $/ 100$

This equation can be used to measure absolute change in TFR.

\section{Results and Discussions}

The estimates of selected reproductive measures of proximate determinants by types of residence in Bangladesh according to BDHS data are given in Table 1. It is found that among urban residents, the use of modern methods has increased by 12 percentage points from 54 percent in 199394 to 66 percent in 2014 while in rural areas it is increased by18 percentage points from 43 percent in 1993-94 to 61 percent in 2014. However in Bangladesh, the use of modern contraceptive method has increased by 17.6 percentage points from 44.7 percent in 2004 to 62.3 percent in 2014 . Table 1 also shows that for all the surveys contraceptive use effectiveness increases gradually in both areas of Bangladesh.

In rural areas, women have a longer mean duration of postpartum insusceptibility (12.46 months in 1993, 9.84 months in 2004 and 8.18 in 2014) than their counterparts in urban areas with a mean duration of 11.06 months in 199394, 8.07 in 2004 and 7.39 in 2014. This could be the fact that women in rural areas breastfeed for longer durations which increase the period of amenorrhea than women in urban areas. This could be because women living in rural areas are more likely to hold on to traditional sexual taboos of not having sexual intercourse while breastfeeding than urban women. Women in urban areas have more access to education and better jobs making them have lesser time to breastfeed. 
In urban areas, total abortion rate (TAR) increased from 0.38 in $1993-94$ to 0.56 in 2004 , declining again to 0.34 in 2014. A similar picture emerges when rural area is considered. The total abortion rate increased from 0.31 in 1993-94 to 0.46 in 2004, declining again to 0.29 in 2014.

Table 1. Estimates of selected reproductive measures of proximate determinants by types of residence in Bangladesh according to BDHS data

\begin{tabular}{|l|c|c|c|c|}
\hline $\begin{array}{c}\text { Types of Residence and } \\
\text { Survey year }\end{array}$ & $\begin{array}{c}\text { Prevalence of } \\
\text { contraceptive use (u) }\end{array}$ & $\begin{array}{c}\text { Average use } \\
\text { Effectiveness (e) }\end{array}$ & $\begin{array}{c}\text { Postpartum } \\
\text { infecundability } \\
\text { (in months) }\end{array}$ & $\begin{array}{c}\text { Total abortion rate } \\
\text { (TAR) }\end{array}$ \\
\hline Urban & 0.54 & 0.90 & 11.06 & 0.38 \\
$1993-94$ & 0.63 & 0.90 & 8.07 & 0.56 \\
2004 & 0.66 & 0.91 & 7.39 & 0.34 \\
2014 & & & 12.46 & 0.31 \\
\hline Rural & 0.43 & 0.91 & 9.84 & 0.46 \\
$1993-94$ & 0.57 & 0.91 & 8.18 & 0.29 \\
2004 & 0.61 & 0.93 & 12.34 & 0.37 \\
2014 & & & 9.46 & 0.52 \\
\hline Total & 0.45 & 0.91 & 0.01 & 0.30 \\
$1993-94$ & 0.58 & 0.91 & \\
2004 & 0.62 & 0.92 & \\
\hline
\end{tabular}

Table 2 shows the estimated indices of the proximate determinants of fertility by urban and rural women in Bangladesh. Among the indices, the contribution of contraception is the most prominent factor in urban areas. The index value decreased from 0.47 in 1993-94 to 0.39 in 2004 and this value declined to 0.35 in 2014 . But the index of postpartum infecundability shows an increasing trend. This indicates a decreasing effect on fertility. However, in urban areas, the effect of marriage is higher on fertility than rural areas throughout the whole three surveys.

The index of contraception is higher in rural areas $(0.57$ in 1993-94, 0.44 in 2004 and 0.38 in 2014) than in the urban areas; an indication of lower contraceptive use among evermarried women living in the rural areas than those living in the urban areas. The reason behind this may be due to higher contraceptive prevalence in the urban areas than rural areas and the increase in educational attainment in the urban areas than the rural areas. The inhibition effect of abortion is greater among women in urban areas than rural areas. The index of abortion among women in the rural areas was 0.95in 1993-94 and 0.92 in 2004 and 0.93 in 2014 whereas in the urban areas the indices were 0.92 in 1993-94,0.87 in 2004 and0.90 in 2014.

The indices of postpartum infecundability in the rural areas were 0 .65in 1993-94, 0.71in 2004, and 0.75in 2014. On the other hand, in the urban areas, those indices were 0.68 in 1993-94, 0.753 in 2004 and 0.77 in 2014. This implies that the index of postpartum infecundability was very high in the urban areas than that of the rural areas. Contraception is an important proximate determinant for fertility decline not only in urban areas but also in rural areas of Bangladesh during the study period. In the total sample, the index of contraception has the most fertility inhibiting effect followed by indices of postpartum infecundability, marriage and abortion between the period 1993-94 and 2014.

Table 2. Changes in the Proximate Determinants of Fertility by Urban and Rural Residence of Bangladesh: 1993-94 to 2014 BDHS

\begin{tabular}{|l|c|c|c|c|c|}
\hline $\begin{array}{c}\text { Types of Residence } \\
\text { and Survey year }\end{array}$ & $\begin{array}{c}\text { Index of } \\
\text { marriage } \\
\left(\boldsymbol{C}_{\boldsymbol{m}}\right)\end{array}$ & $\begin{array}{c}\text { Index of } \\
\text { contraception } \\
\left(\boldsymbol{C}_{\boldsymbol{c}}\right)\end{array}$ & $\begin{array}{c}\text { Index of } \\
\text { abortion } \\
\left(\boldsymbol{C}_{\boldsymbol{a}}\right)\end{array}$ & $\begin{array}{c}\text { Index of postpartum } \\
\text { infecundability }\left(\boldsymbol{C}_{\boldsymbol{i}}\right)\end{array}$ & TFR (estimated) \\
\hline Urban & 0.80 & 0.47 & 0.92 & 0.68 & 3.6 \\
$1993-94$ & 0.72 & 0.39 & 0.87 & 0.75 & 2.8 \\
2004 & 0.72 & 0.35 & 0.90 & 0.77 & \\
2014 & & & & & \\
\hline Rural & 0.75 & 0.57 & 0.95 & 0.65 & \\
$1993-94$ & 0.72 & 0.44 & 0.92 & 0.71 & \\
2004 & 0.71 & 0.38 & 0.93 & & \\
2014 & 0.76 & 0.57 & 0.94 & 0.65 & \\
\hline Total & 0.73 & 0.43 & 0.90 & 0.72 & \\
$1993-94$ & 0.71 & 0.38 & 0.90 & 0.75 & \\
2004 & & & & \\
2014 & & & & \\
\end{tabular}


Table 3 and Figure 1show that relative contribution of the indices on fertility by urban and rural residence of Bangladesh. From table 3 demonstrate that contraception had the highest fertility inhibiting effect in both the urban and rural areas of Bangladesh. The index of contraception had the highest percentage fertility inhibition effect in both rural areas and urban areas in all the three periods with the index having higher percentages in the urban areas than the rural areas. An examination of the changes in the proximate determinants from Table 3 and Figure1 shows that the relative contribution of contraception was higher for women who are resident in urban areas (46.5 percent in 1993-94, 48.3 percent in 2004 and 51.7 percent in 2014) than their counterpart in the rural areas (39.5 in 1993-94, 46.3 percent in 2004 and 49.8 percent in 2014). The relative contribution of postpartum infecundability inhibited fertility reduced from 32.9 percent in $1993-94$ to 20.3 percent in 2014 in the rural areas while it reduced from 28.5 percent in 1993-94 to18.1 percent in 2014 in the urban areas (see Table 3 and
Figure 1). However fertility inhibiting effect is due to marriage variable was higher in rural than urban areas of Bangladesh. Delayed marriage inhibited fertility by 23.1 percent in 1993-94, 22.5 percent in 2004 and 24.0 percent in 2014 in the rural areas while it increased from 17.9 percent in 1993-94 to 22.2 percent in 2004 and again increased slightly to 22.6 percent in 2014 in the urban areas of Bangladesh.

The proximate determinants model is usually multiplicative. It can be considered as additive for measuring the fertility inhibiting effects. According to Bongaarts and Potter ${ }^{4}$, perishing of these effects can be made for declining fertility in TFR. The decompositional change in TFR by residence in Bangladesh between 1993 and 2014 is represented in Table 4.

Table 3. Estimates of the relative contribution of the indices on fertility by Urban and Rural Residence of Bangladesh: 1993-94 to 2014 BDHS

\begin{tabular}{|l|c|c|c|c|c|}
\hline $\begin{array}{c}\text { Types of } \\
\text { Residence and } \\
\text { Survey year }\end{array}$ & Marriage & Contraception & Abortion & Insusceptibility & Total \\
\hline Urban & 17.9 & 46.5 & 7.1 & 28.5 & 100.0 \\
$1993-94$ & 22.2 & 48.3 & 9.9 & 19.5 & 100.0 \\
2004 & 22.6 & 51.4 & 8.0 & 18.1 & 100.0 \\
2014 & 23.1 & 39.5 & 4.5 & 32.9 & 100.0 \\
\hline Rural & 22.5 & 46.3 & 6.9 & 24.4 & 100.0 \\
$1993-94$ & 24.0 & 49.8 & 5.9 & 20.3 & 100.0 \\
2004 & & & & \\
2014 &
\end{tabular}

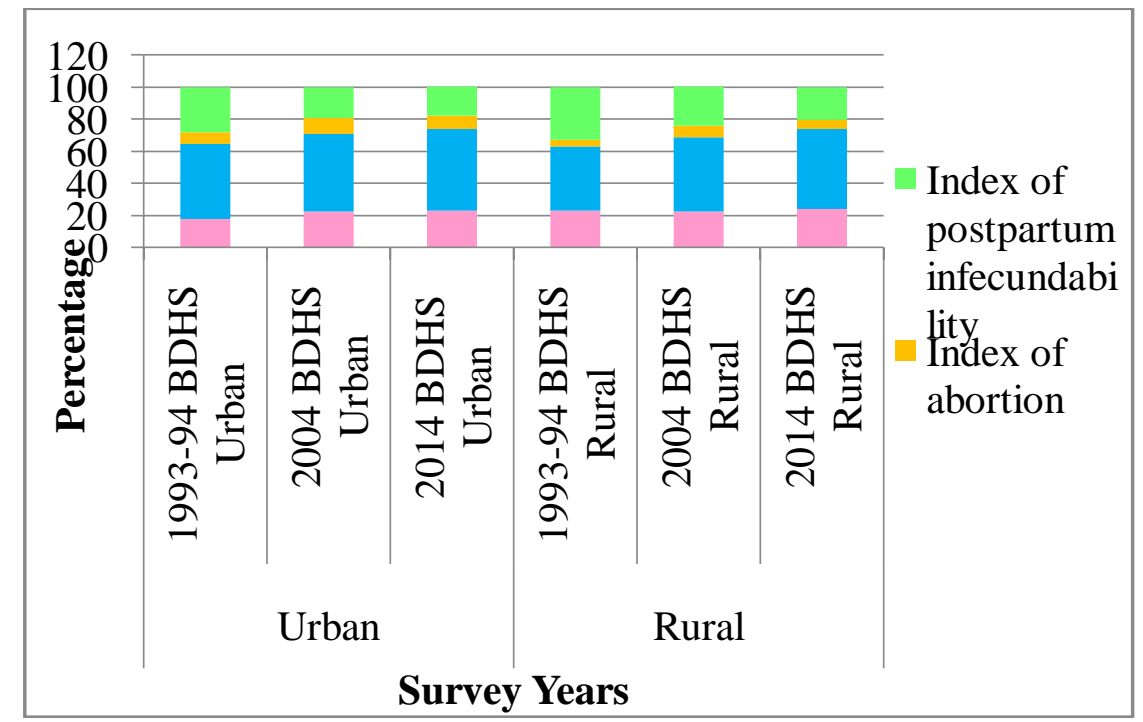

Fig. 1. Relative contribution due to the proximate determinants by region of residence in Bangladesh: 1993-94 to 2014

The results from decomposition method are standardized. These standardized results and absolute changes in TFR considering the contributions made by different proximate variables are also presented in Table 4.The negative sign indicates fertility reducing effects of the determinants. The results shown in Table 4 indicate that the TFR declined by 25.3 percent or absolutely 0.91 births from 3.6 births in 1993-94 to 2.69 births in 2014 among women who reside in urban areas of Bangladesh. 
The decomposition analysis shows that this decline in fertility has been occurred due to delay marriage, a decline of 10.3 percent (absolutely 0.3 birth per woman), a 25.2 percent (absolutely 0.9birth per woman) decline due to an increase of contraception practice, a 14 percent (absolutely 0.5 birth per woman) increase due to shortening of the duration of postpartum infecundability, a 2.3 percent decline (absolutely 0.1 birth per woman) due to an increase in the practice of induced abortion , and a 1.6 percent decline due to increase interaction factor. Results also show that the fertility decline was higher among women who were residents in rural areas of Bangladesh (28.7 percent) or absolutely 1.1 births during 1993-94 to 2014.This can be attributed to a 32.7 percent (absolutely 1.3 births per woman) decline due to increasing contraceptive practice $6.3 \%$ (absolutely 0.3 birth per woman).

Table 4. Decomposition of the changes in total fertility rate (TFR) by residence from selected period in Bangladesh

\begin{tabular}{|c|c|c|c|c|}
\hline \multirow[t]{2}{*}{ Factors responsible for fertility change } & \multicolumn{2}{|c|}{ 1993-94 to 2004} & \multicolumn{2}{|c|}{ 1993-94 to 2014} \\
\hline & Urban & Rural & Urban & Rural \\
\hline \multicolumn{5}{|l|}{ Percentage of change in TFR } \\
\hline Proportion of woman married $(\mathrm{Cm})$ & -9.9 & -3.1 & -10.3 & -6.3 \\
\hline Contraceptive practice $(\mathrm{Cc})$ & -17.8 & -23.0 & -25.2 & -32.7 \\
\hline Induced abortion $(\mathrm{Ca})$ & -5.0 & -3.7 & -2.3 & -2.6 \\
\hline Duration of postpartum infecundability $(\mathrm{Ci})$ & 11.2 & 9.3 & 14.0 & 16.1 \\
\hline Interaction & -0.2 & -1.0 & -1.6 & -3.3 \\
\hline Total & -21.7 & -21.4 & -25.3 & -28.7 \\
\hline \multicolumn{5}{|l|}{ Distribution of percentage in TFR } \\
\hline Proportion of woman married (Cm) & -45.7 & -14.3 & -40.7 & -21.7 \\
\hline Contraceptive practice $(\mathrm{Cc})$ & -82.0 & -107.4 & -99.5 & -113.7 \\
\hline Induced abortion $(\mathrm{Ca})$ & -23.1 & -18.0 & -9.0 & -9.1 \\
\hline Duration of postpartum infecundability $(\mathrm{Ci})$ & 51.8 & 43.5 & 55.5 & 56.0 \\
\hline Interaction & -1.1 & -4.5 & -6.3 & -11.4 \\
\hline Total & -100 & -100 & -100 & -100 \\
\hline \multicolumn{5}{|l|}{ Absolute change in TFR } \\
\hline Proportion of woman married $(\mathrm{Cm})$ & -0.4 & -0.1 & -0.3 & -0.3 \\
\hline Contraceptive practice $(\mathrm{Cc})$ & -0.6 & -0.9 & -0.9 & -1.3 \\
\hline Induced abortion $(\mathrm{Ca})$ & -0.2 & -0.1 & -0.1 & -0.1 \\
\hline Duration of postpartum infecundability $(\mathrm{Ci})$ & 0.4 & 0.4 & 0.5 & 0.7 \\
\hline Interaction & -0.0 & -0.0 & -0.1 & -.1 \\
\hline Total & -0.8 & -0.7 & -0.9 & -1.1 \\
\hline
\end{tabular}

The findings of the study also show that women who living in rural areas had a longer mean duration of postpartum infecundability than their counterparts in urban areas. In 1993-94, 54.2 percent of women from urban areas used contraceptive. The percentage uses of contraceptive were 62.7 in 2004 and 65.9 in 2014, respectively. On the other hand, the percentage uses of contraceptive among rural women were 43.3 in 1993-94, 56.6 in 2004 and 61.1 in 2014.

The indices of the proximate determinants of fertility were calculated using the Bongaarts et al. (1983) model for the analysis of proximate determinants of fertility. This study indicates that in all survey years included in this study contraception had the highest effect on fertility decline in urban and rural areas of Bangladesh. Previous study conducted in Bangladesh also found similar result (Mahjabeen, 2011; Islam et.al 2003). The contraception would have played its more adequate role as the major fertility inhibiting factor if the users would prefer modern contraceptive methods than traditional methods.

The index of contraception practice had the highest fertility inhibition effect in 1993-94, 2004and 2014 for both rural and urban areas with the urban areas having higher fertility inhibiting effect due to increase contraception practice, followed by indices of marriage, abortion and postpartum infecundability in that order. Previous study conducted in Bangladesh also found similar result (Mahjabeen et al., 2011; Islam et al. 2003). It is noted that with the exception of postpartum insusceptibility the values of other three indices (marriage, contraception and induced abortion) are 
in the declining trend in both areas of Bangladesh, which eventually proves fertility decline in Bangladesh. Before 1990s, postpartum infecundability was considered as major factor for reducing fertility in Bangladesh but in 1993/94, contraception had become most potential factor for fertility decline. The fertility-inhibiting effect of contraception is still in an increasing tendency ${ }^{8}$. The increasing practice of contraception use, decrease in currently married women and increase in proportion of induced abortion are the main causes for fertility decline in Bangladesh. Inboth urban and rural areas, an increase trend in the fertility inhibiting effect is found.

Effect of marriage is found as the second most responsible factor for fertility decline. The value of $\mathrm{Cm}$ is decreasing; an indication of increasing effect of marriage as inhibiting fertility factor among urban and rural areas. Similar results were found in Ethiopia ${ }^{12}$.

It is also observed that abortion has smaller effect for fertility decline than the other two factors in Bangladesh. Urban areas show higher effect of induced abortion on fertility decline than rural areas.

\section{Conclusions}

The fertility in rural areas is still above the urban areas of Bangladesh. However, fertility in urban areas is below the replacement level in last couple of years. Our study indicates that contraception in both rural and urban areas had the highest fertility- inhibiting effect followed by married proportion and postpartum infecundability. The effects of practice of induced abortion were the lowest. It can be concluded that among the four proximate determinants, the practice of contraception use was the main cause for fertility changes in urban and rural areas of Bangladesh. Conclusion can be drawn from our study findings that the fertility in Bangladesh can be reduced in future with increasing the practice of contraceptive use. The programs should be focused on creating awareness of early marriage and disadvantage of early marriage especially in rural areas of Bangladesh. Government should take necessary steps to increase female education. The existing national family planning program should be strengthened in order to achieve higher effectiveness of contraceptive use. This can decrease the TFR especially in rural areas where fertility is still higher than the replacement level.

\section{References}

1. Amin, R., J. Chowdhury., A.U. Ahmed., R.B. Hill. and M. Kabir, I993. Reproductive change in Bangladesh: Evidence from recent data. Asia-Pacific Population Journal. 8(4), 39- 58.

2. Bangladesh Bureau of Statistics (BBS). 2014. Statistical year book of Bangladesh, $34^{\text {th }}$ edition.

3. Bongaarts, J., 2002. Completing the Fertility Transition. Population Bulletin of the United Nations.Special Issue Nos. 48/49, 288-307.

4. Bongaarts, J. and R.G. Potter., 1983. Fertility, Biology and Behavior: An Analysis of the Proximate Determinants. Academic Press, New York.

5. Cleland. J., 1994. Fertility levels and trends in Bangladesh. Bangladesh Fertility Survey, 1989. Secondary Analysis.

6. Hussein E. M.and Shawky G. A., 1995. Fertility levels and determinants in Egypt. in Perspectives of Fertility and Family Planning in Egypt. Results of further analysis of the 1992 Egypt Demographic and Health Survey, Cairo, Egypt, National Population Council, 31-53.

7. Islam M. M., M.A. Islam. and N. Chakroborty., 2003. Fertility Transition in Bangladesh: understanding the role of the proximate determinants. Journal of biosocial Science. 36, 351-369.

8. Mahjabeen T. and A. K. Imran., 2011.Analyzing Bongaarts model and its applications in the context of Bangladesh.19th international congress on modeling and simulation, Perth, Australia.12-16 December, 2011.

9. Majumder N. and F. Ram, 2015. Explaining the Role of Proximate Determinants on Fertility Decline among Poor and Non-Poor in Asian Countries. PLoS ONE.

10. Mitra S. N., M. N. Ali., S. Islam., A. R. Cross. and T. Saha. 1994. Bangladesh Demographic and Health Survey 1993-1994. Mitra Associates, Dhaka, Bangladesh.

11. National Institute of Population Research and Training (NIPORT), Mitra and Associates, and ICF International. Bangladesh Demographic and Health Survey 2014. Dhaka, Bangladesh and Calverton, Maryland, USA: Mitra and Associates, and ICF International, 2016.

12. Teklu H., A. Sebhatu. and T. Gebreselassic., 2013. Components of Fertility Change in Ethiopia: Further Analysis of the 2000, 2005 and 2011 Demographic and Health Surveys DHS Further Analysis Reports No.80. Calverton, MD: ICF International, 2013. 